\title{
PLACEBO EQUAL TO NALBUPHINE FOR PRURITUS IN PEDIATRICS
}

Nao Nakatsuka BSc ${ }^{1}$, Sean C Minogue FFARCSI ${ }^{1}$, Joanne Lim MASc ${ }^{1}$,Carolyne J Montgomery FRCP ${ }^{1}$, Colleen A Court BSN ${ }^{1}$, J Mark Ansermino FFA (SA) ${ }^{1}$, Stephan Malherbe $\mathrm{FRCP}^{2}$, Yvonne Csanyi-Fritz $\mathrm{FRCP}^{1}$, Ramona A Kearney FRCP ${ }^{2}$, Leeann Phillips $\mathrm{BSc}^{2}$, Kathy Reid $\mathrm{BSc}^{2}$

${ }^{1}$ BC Children's Hospital, 4480 Oak Street, Vancouver, BC V6H 3V4

${ }^{2}$ University of Alberta Hospital, 8440-112 Street, Edmonton, Alberta T6G 2B7

\section{INTRODUCTION}

The purpose of this investigation was to evaluate the efficacy of nalbuphine, a partial opioid agonistantagonist, to treat post-operative opioid-induced pruritus $(\mathrm{Pr})$ in a pediatric population.

\section{METHODS}

After approval by the University Research Ethics Boards, the dual centre study planned to recruit 268 subjects, age $\geq 7$, receiving continuous opioid analgesia post-operatively who understood the self-report Colour Analogue Scale (CAS) to score pruritus intensity (PrI). Sample size was estimated to demonstrate a $25 \%$ improvement compared to placebo $(\alpha=0.05$ and $1-\beta=0.8$ ). Subjects who reported PrI score $\geq 5 / 10$ were randomized to treatment with nalbuphine $50 \mathrm{mcg} / \mathrm{kg}$ IV (max $5 \mathrm{mg}$ ) or saline placebo. PrI, analgesia (VAS), sedation (5 point score), and side effects of headache, vomiting, and dizziness (yes/no) were recorded at 30 and $60 \mathrm{~min}$. A Pruritus Intensity Difference (PrID) of $\geq 50 \%$ was considered a positive outcome. Subjects with PrI score $\geq 5 / 10$ at $60 \mathrm{~min}$. received nalbuphine $50 \mathrm{mcg} / \mathrm{kg}$ IV (max $5 \mathrm{mg}$ ).

\section{RESULTS}

Of 259 subjects, 212 consented to the study and of these 184 received opioids. The median age was $13 \mathrm{yr}$ (range 7-19) and median weight was $51 \mathrm{~kg}$ (range 19.6-134.8). PrI $\geq 5 / 10$ occurred in 37 (20.1\%) subjects. The CAS was well accepted by all subjects. The incidence of Pr was highest in the PCA group (46\%), versus continuous opioid infusion (27\%) and epidural (27\%). Pr occurred over a wide range of opioid doses (9.4-63.2 $\mathrm{mcg} / \mathrm{kg} /$ hour IV morphine). Epidural hydromorphone resulted in a lower incidence of Pr than intravenous morphine (29.7\% vs. $67.6 \%)$. PrID of $\geq 50 \%$ was achieved in $21(56.8 \%)$ subjects. There was no benefit of nalbuphine (55.6\%) compared to saline (57.9\%) (Figure 1). No increased sedation or reversal of analgesia was noted. Nalbuphine at $60 \mathrm{~min}$, for $\operatorname{PrI} \geq 5$, was given to 8 subjects (13.5\%). Of these, 3 received a cumulative dose of $100 \mathrm{mcg} / \mathrm{kg}$ IV (max $10 \mathrm{mg}$ ) and $3 / 3(100 \%)$ had a PrID $\geq 50 \%$.

\section{DISCUSSION}

Saline placebo was as effective nalbuphine $50 \mathrm{mcg} / \mathrm{kg}$ in treating pruritus. The CAS score and PrID proved to be robust instruments for measuring PrI and warrant further investigation with alternate doses, agents or pruritus models. 